\title{
Invited review: Experimental design, data reporting, and sharing in support of animal systems modeling research ${ }^{1}$
}

\author{
J. P. McNamara, ${ }^{\star 2}$ M. D. Hanigan, $†$ and R. R. White $₫ \S$ \\ *Department of Animal Sciences, Washington State University, Pullman 99164 \\ †Department of Dairy Science, and \\ ‡Department of Animal Sciences, Virginia Tech, Blacksburg 24061 \\ $\S N a t i o n a l$ Animal Nutrition Program, University of Kentucky, Lexington 40506
}

\begin{abstract}
The National Animal Nutrition Program "National Research Support Project 9" supports efforts in livestock nutrition, including the National Research Council's committees on the nutrient requirements of animals. Our objective was to review the status of experimentation and data reporting in animal nutrition literature and to provide suggestions for the advancement of animal nutrition research and the ongoing improvement of field-applied nutrient requirement models. Improved data reporting consistency and completeness represent a substantial opportunity to improve nutrition-related mathematical models. We reviewed a body of nutrition research; recorded common phrases used to describe diets, animals, housing, and environmental conditions; and proposed equivalent numerical data that could be reported. With the increasing availability of online supplementary material sections in journals, we developed a comprehensive checklist of data that should be included in publications. To continue to improve our research effectiveness, studies utilizing multiple research methodologies to address complex systems and mea-
\end{abstract}

\footnotetext{
Received August 23, 2015.

Accepted August 14, 2016.

${ }^{1}$ This work was supported in part by NRSP 0009: National Animal Nutrition Program; and by CREES research project NC 2040: Metabolic relationships in supply of nutrients for lactating cows. The National Animal Nutrition Program (NANP) Coordinating Committee is composed of Gary Cromwell (University of Kentucky), Phillip Miller (University of Nebraska), Jack Odle (North Carolina State University), Mark Hanigan (Virginia Tech), William Weiss (The Ohio State University), Mary Beth Hall (USDA-Agricultural Research Service), Mike Galyean (Texas Tech), Todd Applegate (Purdue University), and Donald Beitz (Iowa State University). The NANP Modeling Subcommittee comprises Mark Hanigan (Virginia Tech), Brian Kerr (USDA-Agricultural Research Service), Ermias Kebreab (University of California-Davis), John McNamara (Washington State University), Luis Tedeschi (Texas A\&M University), Mike VandeHaar (Michigan State University), Nathalie Trottier (Michigan State University), and Roselina Angel (University of Maryland).

${ }^{2}$ Corresponding author: mcnamara@wsu.edu
}

sure multiple variables will be necessary. From the current body of animal nutrition literature, we identified a series of opportunities to integrate research focuses (nutrition, reproduction and genetics) to advance the development of nutrient requirement models. From our survey of current experimentation and data reporting in animal nutrition, we identified 4 key opportunities to advance animal nutrition knowledge: (1) coordinated experiments should be designed to employ multiple research methodologies; (2) systems-oriented research approaches should be encouraged and supported; (3) publication guidelines should be updated to encourage and support sharing of more complete data sets; and (4) new experiments should be more rapidly integrated into our knowledge bases, research programs and practical applications.

Key words: nutrition, agricultural animals, models, experimental design, data sharing

\section{INTRODUCTION}

A mathematical model is a quantitative representation of measurable natural phenomena (Ford, 2009). Within animal sciences, mathematical models have quantified metabolism in specific organs (Freetly et al., 1993; Hanigan and Baldwin, 1994; Hanigan et al., 2007, 2009; Huber et al., 2014), whole-animal nutrient partitioning and the role of nutrition in reproduction (Baldwin et al., 1987c; Baldwin and Sainz, 1995; Kebreab et al., 2004; McNamara and Shields, 2013; Lean et al., 2016), animal performance (McMillian, 1981; Brotherstone et al., 2000; Grossman et al., 2000; Schinckel et al., 2003), farm systems (Rotz et al., 2005; St-Pierre, 2007; Beukes et al., 2008), and environmental impact (Schils et al., 2007; Beauchemin et al., 2010; Del Prado et al., 2013).

Systems approaches and mathematical models have been used in both research and application to great effect to synthesize the current body of literature, identify gaps within current understanding, and quan- 
titatively evaluate biological relationships (France and Thornley, 1984; Baldwin, 1995; St-Pierre, 2001; Dym, 2004; Thornley and France, 2006; Ford, 2009; Lean et al., 2016). Although by necessity, many specific studies focus on only one or a few elements of the system (metabolites, pathways, cells, organs, animals, herds), a systems approach is, at its simplest, a recognition and, at best, a full integration of all new information on any piece of the system into the system as whole (see several chapters in Baldwin, 1995). Models by necessity are simplifications, but as our understanding of biology is furthered through basic research, so too must the intricacy of the models used to summarize that biology, whether for research purposes or practical application (Nicholson et al., 2004). Several factors constrain the use of models, including a lack of knowledge of their use in research (not just for on-farm application); insufficient funding and cooperation among universities; and publication constraints that limit the amount of data reported. Some of these barriers are now breaking down. A substantial amount of input data is required to appropriately parameterize complex models (Cobelli et al., 1979; Carson et al., 1981; Brun et al., 2001; Cornish-Bowden, 2005). In the current body of animal science literature, inconsistent and incomplete reporting of data frequently prohibits the efficient advance of modeling research efforts.

In partial fulfillment of our role as a National Research Support Committee, our objective in this paper was to review the status of experimentation and data reporting in animal nutrition literature and to provide suggestions for the advancement of animal nutrition research and the ongoing improvement of field-applied nutrient requirement models. Thus, we provide a synopsis on the purposes and uses of experimental designs and mathematical models, and highlight opportunities for future experiments, coordinated among researchers, to contribute to model development that represents our knowledge base leading to future research directions and practical field applications of new scientific knowledge.

\section{A QUANTITATIVE APPROACH TO BIOLOGY}

Animal sciences research is, in large form, quantitative; that is, it attempts to define specific relationships of biological processes over time such as growth, reproduction, and milk production (France and Thornley, 1984; Baldwin, 1995; Mogilner et al., 2006; Thornley and France, 2006; Laubichler and Müller, 2007). A rich history of focused, quantitative research has led to our extensive knowledge base and ability to predict requirements or performance quite well in a wide range of animal production systems (Brody, 1945; Kleiber, 1961;
Blaxter, 1989). To make practical recommendations for feeding, genetic selection, breeding, housing, and other management strategies, stakeholders require quantitative relationships that define expected outcomes as a function of specific inputs. Nutritionists, for example, routinely use expected animal performance (milk yield, BW gain, egg production, or wool growth) to calculate feed inputs required (nutrient content and DMI) and the lowest cost diet that achieves those nutrient inputs. The same is true in genetic selection: a known improvement with a known variation is to be expected from mating animals with given breeding values. Reproductive management is quantified as the improvement in pregnancy rate or eggs produced per day expected from certain genetic selection, nutritional, and management strategies.

The examples listed above have primarily focused on the whole-animal or farm level for practical application; however, we have known for some time that it is the complex molecular, cellular, and organismal biology that results in desired practical outcomes, and as such, basic biological science research is a key element of animal sciences. Although basic fundamental research and research in application do not always have similar goals, in much of the animal sciences, including nutrition, studies on mechanisms of cellular or organ function are often conducted within the context of eventual quantitative application in genetics, breeding, or nutrition to enhance knowledge in a more completely quantitative way. One of the founders of systems biology across several levels of biological organization, who helped pave the transition from the more empirical whole-animal work to a more integrated approach, was Ransom Leland (Lee) Baldwin V, who initiated and conducted a 40-yr program of combined practical and basic studies to ask more complex questions to improve animal production (Baldwin, 1995; McNamara, 2012).

Because animal sciences and even animal nutrition research and applications encompass a variety of biological systems and applications, there exists tremendous variation in design, conduct, and reporting of experiments in the animal sciences. This is not inherently a flaw, and there are practical reasons of cost and availability of research funding and resources (too few cows on a university dairy; the expense of doing large-scale studies that take into account most the animal and environmental factors affecting a set of inputs or outputs; the cost of collecting additional samples or conducting additional analyses on existing samples when these measures are not central to the experimenters' hypothesis). There are also philosophical reasons: "I'm a biologist, not a mathematician"; or "that's applied research, not basic science." However, the complexity of research designs and approaches provides a 
challenge to incorporation of findings into the body of knowledge and to practical application. Nevertheless, the animal sciences fields have a rich history of basic and applied mechanistic and quantitative research, and we have accumulated an impressive body of knowledge to guide future research and help support decision making on the farm. One clear example of this continued success is the National Academy of Science's National Research Council (NRC) "Nutrient Requirements" series. For more than a century, scientists have conducted research that has continually added to our quantitative knowledge on feed chemistry, feeding management, nutrient requirements, and expected responses of animals to diets; this new knowledge is encoded in subsequent releases of the NRC series. These models have allowed increasingly accurate and precise management decisions on the farm. In this example, the NRC models by design are aggregated at or close to the animal level (early versions included just "crude protein" or varied milk fat and milk protein together). As animal scientists secured research funding to discover more specific aspects of basic biology, that information was included in the animal-level models, making them somewhat less aggregated and more specific, such as adding limiting amino acids or separating production of milk fat and milk protein. The long-term coordination of basic information to more efficiently describe the applied (animal) situation actually drove a significant amount of research funding. However, the connection between development of these "basic" concepts and field application has been inconsistent and often qualitative in nature. A more specific quantitative approach can be taken, and the continued restraints on funding, resources, people, and time will dictate that we must continually improve the efficiency of our research approaches.

One proven way to achieve this is to take a quantitative approach to all experiments and to closely coordinate research projects. The increasing interest in more integration of genetics, nutrition, and reproduction has arisen from the fact that our body of knowledge and understanding now dictates that we recognize that "nutrition," "genetics," and "reproduction" do not exist, truly, as separate disciplines. In fact, although scientists may concentrate on one specialty, we know that "the cow does it all at the same time" (McNamara and Shields, 2013).

For example, a mathematical model of nutrient use by an animal is a quantitative representation of our understanding of metabolism. It is a structured set of equations that describes metabolic pathways or nutrient use at some level of biological organization. Additional functions, such as reproduction, can be added to such a description of metabolism, or the metabolism functions can be incorporated, possibly in aggregated form, into a reproduction model. In both cases, the links between the systems can be explicitly represented (McNamara and Shields, 2013). It is understood that for purposes of this review, we include all types of models (applied, research; deterministic, stochastic; dynamic, static) without value judgment of one approach or another; rather, our goal is to encourage proper development and application of the modeling technique pertinent to the objective at hand.

A model is built by first identifying the important components of the system being modeled. In the case of some nutrition models, the equations describing rates of nutrient and energy flow among these components are the core of the model. In certain types of metabolic or nutritional models at the cellular, organ, or animal levels, the model is solved by integrating the rate equations for specific animals or specific situations, which can then be adapted to other situations as needed. The NRC nutrient requirement compilations are an example of this approach using a highly aggregated representation of the inputs (nutrient composition and intake) and outputs (growth rate, milk production, reproductive activity) to determine the quantity of each input required to achieve the desired level of production.

Nutrition modeling, however, cannot be separated from the biological sciences and processes, but is in fact a key element of them. Cells do not act randomly; mammary glands do not make a random amount of milk based on whatever genes are being expressed; rather, cellular, metabolic, organ, and whole-animal systems are absolutely, structurally, and functionally quantitative in nature, with a given set of chemical rates and equilibria behind every biological process and output.

With the increased availability and use of highthroughput technologies such as genomic, transcriptomic, proteomic, and metabolomic technologies and the massive expansion of computer storage and processing, one can obtain a large amount of data at several levels of metabolic control. However, obtaining and publishing tables or figures of such data are only the first steps. Quantitative integration of the data across biological processes is possible and should be undertaken to gain a full understanding at the organismal level. Such integration can occur at multiple levels of organization. For example, regression techniques can be used to compare changes in mRNA transcript abundance with enzyme amount or activity or metabolic flux through a pathway. This knowledge can then be incorporated into more complex models to assess the knowledge with respect to function in other tissues or animal subsystems. From this, we can get a more quantitative and complete description of metabolic control, and from there, we can improve selection and application of selection or feeding on the farm. Recently, the USDA National 
Institute of Food and Agriculture (Washington, DC) funding model has taken a dramatic shift to funding more integrated, cross-disciplinary studies. This is a good step, but if it is to succeed fully, more resources must be provided and more incentives must be put in place to encourage scientists to conduct research across disciplines and among various organizations.

The reasons for taking a strict quantitative approach to animal sciences and animal systems research have been well stated previously. An excellent example comes from the introduction to Modeling Ruminant Digestion and Metabolism (Baldwin, 1995): "There is general agreement among most informed authors that products of animal agriculture will continue to contribute to the world food supply. However, the key challenge of ascertaining how much animals should contribute has not been resolved. This is a long-term goal that will require the availability of advanced dynamic, mechanistic models of ruminant digestion and metabolism..." The current systems biology approaches are a continuing example of such an approach.

Another limiting factor in expanding the use of models in animal science research may be the misperception that "models" are only applied science, such as the NRC, and are not applicable to basic biological sciences. The complete refutation of this misperception would fill many books, and indeed has, as many biological scientists, programs, departments, and funding bodies have rejected this notion and conducted excellent quantitative research for 4 decades (Carson et al., 1981; Baldwin, 1995; Cornish-Bowden et al., 2007; Hood and Rowen, 2013; Hood and Price, 2014). The approach has not been as well accepted in animal sciences research but there are notable exceptions (Black et al., 1993a,b; Hanigan and Baldwin, 1994; Beukes et al., 2008; Hanigan et al., 2009; McNamara and Shields, 2013).

In recent years, the term "systems biology" has come into wide use to recognize the interconnections between levels of biological processes (from the molecular to the whole animal) as well as between various disciplines. A large impetus for the increased work in systems biology has been the explosion of techniques for molecular genetics, which demands a systems approach to integrate genomic and transcriptomic knowledge with that of metabolism and end effect. In the animal sciences, much of the model work has applied primarily to "on-farm models" such as the NRC or extension publications on decision support tools for nutrition, reproduction, or health, and there has been less of a modeling approach to basic nutrition research. A systems biology and modeling approach has been in use for many decades and has been highly successful in integration of available concepts and data, in a quantitative manner, to evalu- ate our understanding of animal function (Baldwin et al., 1987a,b,c; Dijkstra et al., 1992, 1993; Black et al., 1993a,b; Cannas et al., 2004; Thornley and France, 2006; Hanigan et al., 2007, 2009; Beukes et al., 2008; McNamara, 2012; McNamara and Shields, 2013). The use of systems models is in keeping with biology: the quantitative output of an individual animals or herd of animals is a mathematically definable function of the underlying chemical processes.

\section{WHAT ARE MATHEMATICAL MODELS AND WHAT CAN THEY DO?}

Models can and do mean many different things. In the context of animal biology, a model can be described as "a simplified description, usually a mathematical one, of a system or process, to assist calculations and predictions" (Oxford Dictionary; http://www.oxforddictionaries.com). Another definition is a representation of the behavior of real devices and objects in a mathematical manner (Dym, 2004; Ford, 2009). Models have been and are a major mechanism of research and application in farm animal nutrition (see Baldwin, 1995, and the many references therein). An imperfect description of animal responses identified by a model highlights the inadequacies in our understanding of the system. Commonly used methods of classifying models, model development, and model testing have been extensively reviewed (Baldwin, 1995; Dym, 2004; Tedeschi, 2006; Thornley and France, 2006; Ford, 2009).

Within energy modeling, 2 general types of models are widely used: nutrient partitioning models (NRC, 2001, 2012, 2016; Fox et al., 2004; Tylutki et al., 2008; Tedeschi et al., 2010) and metabolic models (Baldwin et al., 1987c). Either type of model estimates the performance of an animal when given a specific diet under specific environmental conditions; some also describe the response to a change in nutrients, although the more aggregated models were not necessarily designed for the latter.

Nutrient partitioning models apportion nutrients to supportive (maintenance) costs and among various productive functions according to predetermined rules (Baldwin and Sainz, 1995). These rules may take the form of statements of maintenance requirements, efficiencies of conversion of nutrients to product, and priorities for use of limiting nutrients. The results are summed to predict whole-animal performance. Metabolic models estimate the rates of various biochemical conversions, including those associated with supportive (maintenance) functions and protein and fat synthesis and degradation. Highly aggregated metabolic models can be used to estimate whole-animal performance 
(Baldwin et al., 1987c). Less aggregated, more detailed models may deal with only a single organ or tissue, such as mammary gland (Hanigan and Baldwin, 1994), adipose tissue (Baldwin, 1995; McNamara and Baldwin, 2000; McNamara et al., 2016), or liver (Freetly et al., 1993). Although there is a large body of research on quantitative estimates of obligatory energy and amino acid losses (maintenance) (Moe and Tyrrell, 1975; Ouellet et al., 2002; Agnew et al., 2003) and efficiencies of amino acid (Doepel et al., 2004; Lapierre et al., 2005; Metcalf et al., 2008; Arriola Apelo et al., 2014) and energy use (Moe and Tyrrell, 1975; Schwager-Suter et al., 2001; Olson et al., 2010), we still do not understand, in a quantitatively complete manner, their interactions by various genotypes under varying dietary and management conditions.

The rigor imposed by mathematical modeling directs researchers to important questions and to significant gaps in knowledge. It raises questions that might not otherwise be raised. The simultaneous consideration by a model of many factors raises key questions about interactions among those factors and can aid in the identification and design of experiments. Modeling can help us form specific questions to be addressed by various types of experiments, and thus help us gain efficiency and relevance in research. Modeling, as a component of a research program at any level of biological organization, improves efficiency by reducing inefficiency and redundancy; knowledge encoded in the model can be tested for consistency, accuracy, and precision against existing data, and if it is found to be robust, there is no further need to examine that mechanism. The advancement and growth of systems biology research and bioinformatics research is simply another example of modeling (Ideker et al., 2001; de Jong, 2002; Kitano, 2002).

For example, various models of ruminal digestion and microbial breakdown of feed particles and liquid and solid passage rates may describe animal production with a standard deviation (SD) of $10 \%$ of the mean (Bannink et al., 2000, 2006, 2008; Hanigan et al., 2009), but comparing observational data on nutrient digestion to the model suggests that predictions of fiber and starch digestion are not as robust as one might desire, which likely contributes to errors in predicting production of fermentable carbohydrates and VFA. Such observations highlight the need for more research on carbohydrate degradation in the rumen. Another example that has had serious attention for many years is the lack of studies measuring actual VFA production in the rumen, thereby limiting our ability to form equations and parameters that describe this process better than within a standard deviation of $20 \%$ (concentrations) to $60 \%$ (production) (Bannink et al., 2000, 2006, 2008; Ghimire et al., 2014). This suggests that effort should be focused on the following questions: What exactly more do we need to know about VFA production? If we had more precise estimates of VFA production, what would be the quantitative gain in our knowledge (e.g., to predict within 10 or $20 \%$ instead of $40-60 \%$ )? If we spent the money and time to do such research, what would be the scientific and practical return on investment?'

In addition to being an integral component of nutrition, genetics, and reproduction research, models are useful teaching and extension tools (Thornley and France, 1984; Black et al., 1993b; Passmore and Stewart, 2002; Wilensky and Reisman, 2006). Mathematical models show students or livestock producers how animals respond to key factors, and how the responses can be altered by interacting factors. This can be much more effective than lectures or slide sets, which require the recipient to integrate a large amount of information over time, with the resultant degradation of precision in understanding. A model can point out the effects of decisions on feeding or research problems quite easily to introductory or advanced students.

Models are and have been invaluable guides used daily in livestock feeding programs (NRC, 2001, 2012). They are being used to assist nutritionists and producers in fine-tuning diet formulations to fit variable conditions such as genotype, ambient temperature, and voluntary feed intake (Tylutki et al., 2008). Prospective improvements in efficiency of animal agriculture from the use of more advanced models are promising. To fully realize these potential benefits, a larger quantity and more complete data are needed. Thus, we must improve the consistency and completeness of data reporting and sharing.

\section{EXPERIMENTAL DESIGNS AND ANALYSES IN SYSTEMS RESEARCH}

\section{Past and Future Designs}

The availability of data from an experiment is primarily determined by the experimental design. As our knowledge of animal biology continues to expand, we must set more-complex hypotheses that encompass several systems (cells, organs, animals, herds) in a variety of environmental situations, climatic areas, and often over long periods. In the past, limitations of knowledge, funding, animals, statistical methodology, and most importantly, scientific approach resulted in many smaller studies with narrow focuses, the global applicability of which was often undefinable. These experiments can 
often be aggregated to yield a more comprehensive data set, provided the needed array of inputs required by more complicated models has been reported for all of the experiments, which is often not the case. Contemporary research technologies have expanded to allow relatively low-cost measures of cellular and subcellular processes. The concurrent improved understanding of statistical strategies and analytical programs has facilitated design, implementation, and interpretation of more complex, multivariate experiments. The advantage to these larger experiments is that the data are typically distributed throughout the observed range, yielding complete response surfaces within an experiment as opposed to inferring a response surface from multiple independent experiments.

\section{Experimental Designs}

Factorial experiments designed with 2 levels of each factor are very useful in identifying mechanisms. However, once a mechanism has been identified as being important, follow-up work is required using experimental designs involving several levels of one or more factors, and thus producing further in-depth quantitative understanding. Also, if 2 or more factors are studied, all cell means or regression parameters should be reported or the work will have limited value in the integrative modeling environment. Here we include just a few examples of experimental designs that are useful for answering questions regarding nutritional biology.

Multivariate Analysis. Multivariate analysis quantifies concurrent effects of explanatory variables on multiple response variables. Factorial designs are often required to obtain sufficient data for a multivariate analysis as these designs measure one or more response variables from experimental units treated with unique combination of levels from 2 or more explanatory variables. The most common multivariate statistical procedures include multivariate ANOVA, multivariate regression analysis, principal components analysis, and factor analysis (Hair et al., 2006). Several examples of multivariate analysis are available within the animal science literature (van Milgen and Noblet, 1999; Noguera et al., 2002; Reverter et al., 2004; Todaro et al., 2005). From an experimental standpoint, the principal benefit of multivariate analysis is the control of type I and type II error rates by avoiding several, independent tests of the same explanatory variables on a series of response variables (Haase and Ellis, 1987). From a modeling standpoint, multivariate analysis allows for assessment of the correlations and interdependence among dependent variables, as well as between independent and dependent variables (Haase and Ellis, 1987).
Randomized Complete Block Design. Block designs are commonly used in the animal science literature (Steele and Torrie, 1980; Firkins et al., 1985; Wondra et al., 1995). A randomized complete block design is a unique type of block design that randomly assigns treatments to experimental units within a block where each treatment appears within each block (Ott and Longnecker, 2010). The experimental design is advantageous because it is simple to design, construct, and analyze. However, randomized complete block designs are most useful when comparing relatively few treatment combinations, as treatments must be homogenized within blocks. This design also only controls for only one extraneous source of variability (Ott and Longnecker, 2010). The primary advantage to data from randomized complete block designs within modeling applications is the uniformity of the explanatory parameters, as all treatments must be represented within all blocks.

Latin Square Designs. Latin square designs are widely used and can be very efficient in testing hypotheses about responses to nutrients when animal numbers are limited and especially when the response is likely to be relatively quick or short-lived (Steele and Torrie, 1980; Tempelman, 2004, 2009). An example would be the effect of changing nutrient or physical characteristics of a ruminant diet on the rumen flora and fauna. These adaptations tend to be measured within hours and often are complete within several days. Thus, longer-term experiments need not be conducted. However, that same strength means caution should be applied in extrapolating the effects to any longer period. This is an issue in designs in growing animals with a long growing period (as in cattle) or in lactating cattle, where it is not always likely that the response seen within a few days or weeks will extend over several months. The Latin square design may be inappropriate when it is likely that there will be carryover effects of a treatment into ensuing periods, requiring much longer "washout" periods between treatments. Latin square designs can be used in these situations if it is known that the carryover effects may not be large or last long, and various sources describe these carryover designs (Steele and Torrie, 1980; Tempelman 2004, 2009). As long as these limitations are known, the Latin square can continue to be a very useful design in experimental nutrition.

Split Plot Designs. Practical constraints associated with working with live animals often mean that studies using a large number of treatments with sufficient experimental units are infeasible. Split plot designs apply one factor to a large experimental unit that is then split to smaller units. A second factor is then applied to the smaller units. Split plot designs can have more than one level or organization (split-split-plot, 
split-split-split-plot) and have been used in a variety of applications throughout animal science literature (Wheeler et al., 1990; Hill et al., 1993; McGlone et al., 1993). The primary experimental benefits of split plot designs are the ease of applying treatments and (often) the benefit of improved uniformity of treatment application (Ott and Longnecker, 2010). Much like the basic randomized complete block design, the advantage of a split plot experiment from a modeling perspective is the completeness and uniformity of the data.

Split Plot in Time (Repeated Measures). Repeated-measures designs are a special application of a split plot where sampling time is treated as a subplot. Experimentally, repeated-measures designs make efficient use of resources as multiple responses are collected per subject (Ott and Longnecker, 2010). Because animals are often a constraining factor in experiments, repeated measures are common in animal sciences, and specific resources on running these experiments are available (Gill and Hafs, 1971; Littell et al., 1998; Wang and Goonewardene, 2004). Repeated-measures designs yield particularly useful data as they involve time-series measurements that can usually be used to fit more reliable models than point-in-time, aggregated treatment means.

\section{INFORMATION REQUIREMENTS FOR MODELING STUDIES}

Due to the complexity of existing nutritional knowledge, the more advanced mathematical models require substantial input data to run, evaluate, and parameterize. These are not superfluous additions to the model; they are additions that have been dictated by the knowledge base over time. To improve on current models, the existing body of biological knowledge must be expanded, and the experiments contained in this expansion must describe all inputs in enough detail to allow simulation with current models. The following information deficits represent a few key areas where new data could be collected to improve the efficiency and adequacy of mathematical models commonly used in animal nutrition.

\section{Information for Improvement of Metabolic Models}

For purposes of this discussion, "metabolic models" are used as an example of systems models describing pathway biochemistry and its control and integration in the context of explaining the more aggregated nutritional partitioning models. Nutrient partitioning models also describe differential use of nutrients within animals but at a more aggregated and empirical level that does not generally include pathway biochemistry. Most such models are based on mass respiration calorimetry or comparative slaughter studies that can "partition" carbohydrate, fat, protein, and in some cases, amino acid pools, but do not include specific enzymatic or hormonal control except at an empirical level. Presently, metabolic models depend upon estimates of kinetic parameters (including maximal velocity and affinity constants) of metabolic pathways (Baldwin, 1995; McNamara, 2004). To parameterize, test, or improve these models, direct estimates of these parameters under varying conditions are needed. Arteriovenous difference studies of nutrient uptake and utilization by tissues such as mammary glands, liver, viscera, and hind limbs are particularly valuable in this regard when a range of conditions that can justify both equation forms and parameterization are feasible. If these are not feasible, in vitro studies can provide valuable information on relative changes in metabolism, on tissue- or cell-level equation forms, and on nutrient interactions. These types of studies are especially necessary for tissue-level models. A detailed discussion of the proper role and application of in vitro research and application to whole-animal performance is beyond the scope of this paper, but an excellent discussion can be found in Chapter 6 of Baldwin (1995). For example, by measuring the cost of ion pumping in liver cells in vitro (Milligan and McBride, 1985), of protein turnover cost in mammary cells (Hanigan et al., 2009), or of metabolic flux in adipose tissue lipid synthesis and mobilization (McNamara and Hillers, 1989; McNamara and Baldwin, 2000; McNamara, 2004), better estimates and mechanistic explanations of the costs of maintenance and productive functions at the whole-animal level have been obtained.

There is a pressing need to incorporate metabolic hormones explicitly into metabolic models, but a lack of understanding and knowledge of quantitative relationships remains a barrier. Descriptions of tissue sensitivities to hormones under various conditions are also needed. Estimates of the alteration in kinetic parameters caused by changes in hormone concentrations during different physiological and nutritional states are needed. A widely used metabolic model that simulates bovine metabolism (Baldwin et al., 1987a,b,c) has provided guidance on areas of research that were not present in the literature and would be most applicable to the advancement of that model; however, development efforts geared at generating similar metabolic models in other species or at the organ level will also benefit from this improved information availability. Many examples of such experiments using a combination of animal-level, tissue- and cell-level, and molecular-level data collection can be found in references in Baldwin 
(1995) and in references in recent reviews (McNamara, 2012; McNamara and Shields, 2013).

\section{Information for Improvement of Nutrient Partitioning Models}

Animal-level nutrient requirement models often require fewer inputs than metabolic models. Substantial improvements in these models can be made with more complete reporting of data in experimental studies. In species that have established nutrient requirement models (Fox et al., 1992; NRC, 2001, 2012, 2016; Cannas et al., 2004), a notable opportunity for improvement is in the prediction of intake. Intake varies substantially with feed form, nutrient concentration, productive stage, health status, age, performance level, genetic merit, body fat composition, and many other factors. Without consistent reporting of many of these important indicators, minimal improvement in intake equations can be made. Recent research on "physically effective NDF" and its relation to feed intake in dairy cattle is an excellent example of the need for more detailed and integrated models of digestion, metabolism, and production (Jones, 2014). In the field, we have recognized for many years that there is a relationship among NDF, the form of NDF, plant maturity, forage conservation, and voluntary intake of ruminants, primarily dairy cattle. Several excellent studies have been conducted to describe this relationship precisely, and this work has resulted in on-farm improvement of nutritional efficiency. However, we still do not understand the specific chemical, microbiological, and biological mechanisms that truly drive these animal-level functions. This is an example of "had we had the inclination, resources, and funding" we could have done experiments that measured both the animal-level empirical relations and the underlying biological mechanisms, and we could have reduced the cost and time involved in improving knowledge and application.

Many estimates of patterns and partial efficiencies of energy use are available (for some examples: Lofgreen and Garrett, 1968; Close, 1978; Yan et al., 1997; Tedeschi et al., 2002, 2013; Marcondes et al., 2013), but we need similar data on amino acid utilization. Such estimates are also useful to provide a background for more detailed metabolic studies. We need more quantitative descriptions of the apportionment of energy and amino acids among various function (e.g., protein vs. fat accretion) in situations when these supplies are limiting. Quantitative estimates of the maximum capacities for protein and fat deposition throughout the life cycle and maximum rates of tissue mobilization as lactating animals deplete their body stores are also needed (see, for example, Tedeschi et al., 2013).

\section{Information for the Improvement of All Nutritional Models}

Given the growing interest in nutrigenomics (Müller and Kersten, 2003), inclusion of specific, consistent, and relevant indicators of genotype in manuscripts is imperative to future modeling efforts. Accurately describing genotypes is becoming easier, if not required, in mathematical models of energy use by animals. The proliferation of genomic genotyping tools and the reduction in cost would seem to dictate that all animals should be genotyped using molecular screens to allow use of the data in development of better genetic selection strategies and tools. On a large production study with 60 animals, this would add $\$ 3,000$ to the cost of the experiment at today's prices. Such a cost is not insignificant but it would provide information that should generate great returns on the investment in the future, and the cost of the measurement will continue to fall as techniques improve and volume increases. In the case of smaller metabolism studies, it would be a trivial cost increment and thus should be undertaken.

However, it is not just collecting the genomic data that provides full understanding. Existing knowledge of the role of the gene in regulating cellular function and eventual animal performance must be used to interpret the role of the differences in genotype, or new research must be done to define the full contribution of the genotype and phenotype to eventual production indices. Meaningful discussion among industry stakeholders, geneticists, and nutritionists will be essential in identifying species-specific, appropriate levels of detail for reporting genetic parameters. In poultry, genetic line has been used to identify genotype (Jones et al., 1995); this is a commercially available, relevant metric; however, the short generation interval of poultry results in high turnover of genetic information, even within a line. In beef cattle research, breed has been used to define genotype (Baker and Lunt, 1990; Jenkins and Ferrell, 1994). In the NRC (2016), breed codes were used to incorporate genetic differences into nutrient recommendations. Although reasonably durable because cattle have a long generation interval, there is minimal opportunity to assess the effect of improved genetic merit on animal performance and efficiency with this approach. As our understanding of genetic interactions with animal nutrition improves, the discussion between industry stakeholders and researchers should continue to identify workable parameters that can be used to define animal genotypes consistently. This might be as simple as potential production capacity. Alternatively, genotypes can be defined in terms of parameters such as efficiency of energy or amino acid use, maintenance costs for energy or amino acids, and maximum rates 
and affinity constants for specific metabolic pathways or hormonal functions. At a more specific level, genotype can be defined in terms of specific gene sequences, quantitative trait loci, or single nucleotide polymorphisms.

A further area of opportunity within most models involves the addition of parameters to reflect health status or environmental stress. A multitude of studies have been conducted on the influence of health (Sykes, 1994; Foley et al., 2008; Delgado and Wolt, 2010), housing system (Gentry et al., 2002; Shimmura et al., 2007; Mugnai et al., 2009), and environmental conditions (Black et al., 1993a; Nienaber et al., 1999; West, 2003) on productivity. From these bodies of literature, consensus must be drawn on specific, quantitative metrics that can be incorporated into models estimating nutrient requirements. These data must then be consistently reported in the literature. In the absence of such a consensus, it seems prudent to collect and report the basic environmental parameters during the experiment, which would include among other variables, the mean daily high and low temperatures and dew point and the deviations in those values. These data can be used to describe much of the effect of climate. Use of climate mitigation equipment should also be reported. Wind speed is also useful, but this is more problematic as local wind speed within the facility may not be well represented by the nearest weather station, thus requiring measurements within the facility to gain the needed precision.

Scientists planning particularly large or integrated studies that are likely to yield information useful for building or testing models are encouraged to contact those actively working with related models. It may be that a small change in experimental design and measurements would enhance its usefulness for modeling, without detrimental effects with regard to other objectives of the experiment.

\section{DATA REPORTING AND SHARING}

Consistent and complete data reporting is good research practice and may be the single most important opportunity to advance modeling research efforts. Models, like experiments, are becoming more complex, and substantial data sets are required to parameterize the encoded relationships. Even comparatively simple models such as the NRC nutrient requirement predictions (NRC, 1994, 2001, 2012) and the Cornell Net Carbohydrate and Protein System (Russell et al., 1992; Sniffen et al., 1992; O'Connor et al., 1993; Fox et al., 2004; Tylutki et al., 2008) require a multitude of inputs defining animal, production system, feedstuffs, and the environment. To evaluate these models comprehen- sively, all these input data are required in addition to measures of animal performance. As such information is typically not reported, data mining (retrieving data from the literature) is frequently relied upon, which reduces precision in describing inputs; that is, the tabular mean for an ingredient cannot be expected to represent the exact situation for all experiments. Even that effort is often compromised due to the failure to report the diet and animal conditions in enough detail within the manuscript to allow reconstruction of the missing details. This failure often occurs because this level of data reporting is deemed extraneous to the objectives of the publication and may be removed by authors, reviewers, or editors. There is also the practical limitation in printing many pages of data. However, the advent of online supplements, cheap storage, and instantaneous data transmission makes this point irrelevant. If the large annual investment in animal research is to be fully leveraged, descriptions of the experimental conditions as complete as possible should be included in all publications or made available upon request. A small investment in measurement and reporting will enhance the value of the work by extending the impact of the work beyond the stated experimental objectives to inclusion in a database that could be used for future model development.

Tables 1, 2, and 3 show several examples of phrases frequently found in papers that replace data and the data that should be included in their place. Figure 1 provides a data inclusion checklist for editors, reviewers, or authors. Required data can be roughly divided into 3 classifications: feed information, animal descriptions, and housing/environment. A consistent and complete description of these 3 experimental components, on a treatment-specific basis, could effect substantial improvements in modeling research efficiency.

The NANP is not suggesting that several tables of additional data or raw data numbers be published in paper format. However, we are suggesting that journal management committees discuss and develop ways to publish in electronic format such data from peerreviewed and accepted studies, to be made available to interested researchers. In addition, the NANP is charged with supporting the efforts of the USDA and NRC in improving and publishing the NRC's nutrient requirement updates and, in that capacity, is developing a website and data repository that may be appropriate for publication and sharing of detailed experimental data. We are also not suggesting that authors measure the amino acid composition of all of their feedstuffs in all studies but rather supply sufficient information about ingredients such that this information could be obtained from existing databanks. Given the integrated nature of nutritional biology, we often publish stud- 
Table 1. Phrases used to describe diets within publications and examples of specific numerical data to be reported

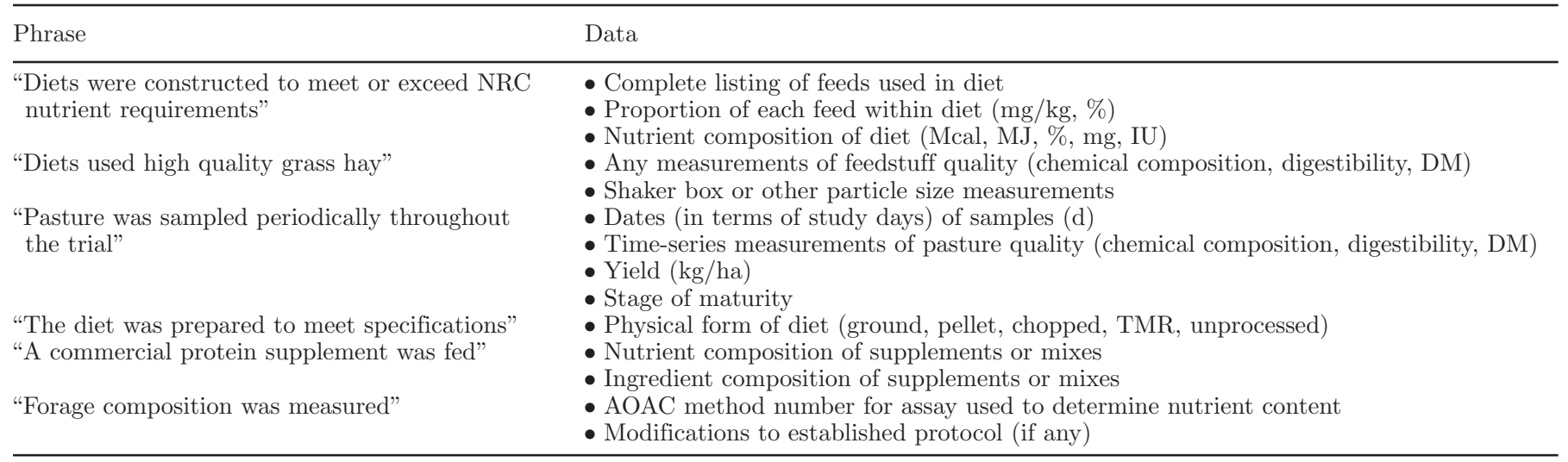

ies on carbohydrates, fats, or proteins and then later discover or admit that a change in one caused a change in another and that such interactions may have more precisely explained the "treatment response." This inefficiency in our research can be diminished quickly if we expend more time and effort in design of more specific and often more complex experiments or provide more complete descriptions of our experiments, so that we can avoid such mistakes in future studies and precisely describe the underlying interactions in nutrient metabolism that affect practical responses to genetics, nutritional, or reproductive management.

\section{Types of Data}

Feed Information. Feed information is reported with great variability across studies, and imprecise statements (Table 1) are frequently used to define diet composition and ingredient quality. Feed composition varies substantially with batch, age, storage method, source, weather, and many other parameters (Kertz, 1998). Although book values can be useful in teaching or extension applications, precise measurements of feedstuff composition should be conducted in research settings. The results of these measurements, naturally, must be reported in publications on a treatment-specific basis. Much like biological understanding, feed evaluation methods have improved with time, and proximate analysis is no longer an adequate description of a feed. Amino acid composition and digestibility affect feed intake and performance of most animals more acutely than dietary CP content (Holsheimer and Veerkamp, 1992; Kerr et al., 2003), and substantial associative effects between energy and protein content have been outlined across species (Oldham, 1984). For example, in addition to feed composition information, the AOAC method number (or the appropriate protocol in other countries or societies) for the assay used to determine composition should be included in the study, along with any modifications to the established protocol.

Table 2. Phrases used to describe housing and environmental conditions and examples of specific numerical data to be reported

\begin{tabular}{|c|c|}
\hline Phrase & Data \\
\hline "Pigs were housed in standard pens" & $\begin{array}{l}\text { - Dimensions of housing unit }\left(\mathrm{m}^{2}\right) \\
\text { - Number of animals per housing unit (n) } \\
\text { - Feeder and waterer space per animal } \\
\text { - Type of housing used }\end{array}$ \\
\hline "The trial took place over summer of $2013 "$ & $\begin{array}{l}\text { - Temperature (mean, low, high) } \\
\text { - Wind speed }(\mathrm{km} / \mathrm{h}) \\
\text { - Dew point }\end{array}$ \\
\hline "Cooling mechanisms were used" & $\begin{array}{l}\text { - Description of cooling system } \\
\text { - Temperature in housing system during cooling } \\
\text { - Temperature between cooling events }\end{array}$ \\
\hline "Animals were brought to the parlor twice daily" & - Exercise level: distance walked, terrain description \\
\hline "Animals were kept on native range" & $\begin{array}{l}\text { - Terrain description (hilly, flat) } \\
\text { - Stocking density } \\
\text { - Forage mass per area }\left(\mathrm{kg} / \mathrm{m}^{2}\right)\end{array}$ \\
\hline "Two animals were culled for health reasons" & $\begin{array}{l}\text { - Exact reason for culling } \\
\text { - Frequency of illness (specific) within culled and retained animals } \\
\text { - Any available subclinical indicators of illness }\end{array}$ \\
\hline
\end{tabular}


Table 3. Phrases used to describe animals and animal performance and examples of specific numerical data items to be reported

\begin{tabular}{ll}
\hline Phrase & Preferred data \\
\hline "Weaned animals were used" & $\bullet$ Average starting age \\
& $\bullet$ Average ending age \\
& $\bullet$ Average starting BW \\
"Mature cows" & $\bullet$ Parity ending BW \\
"Body composition was estimated" & $\bullet$ Prame size or height \\
& $\bullet$ BCS thickness \\
"A highly productive line and a lowly productive line" & $\bullet$ Lean tissue growth rate \\
& $\bullet$ Milk production \\
& $\bullet$ Mature BW \\
"Sows were previously fed a commercial, balanced ration" & $\bullet$ Genotypic measures (if available) \\
"Various metabolic parameters were measured" & $\bullet$ Previous plane of nutrition \\
"Estrus was synchronized" & $\bullet$ Blood metabolite concentrations (all available) \\
& $\bullet$ Hormone measurements (all available) \\
"Several additional performance indicators were measured" & $\bullet$ Modific program used \\
& $\bullet$ Conception rate program \\
& $\bullet$ Average daily gain \\
& $\bullet$ Lean tissue gain \\
& $\bullet$ Milk yield \\
& $\bullet$ Milk composition
\end{tabular}

Housing and Climate Data. Thorough descriptions of the housing system and climate conditions should be reported. Heat stress is an economically important problem in many parts of the world (St-Pierre et al., 2003). Reporting of standard climate parameters for each experimental unit can help researchers solidify quantitative representations of animal performance responses to temperature stress. This is paramount given growing concerns about climate change (IPCC, 2007) and the future security of the food supply (FAO, 2009). Several studies have identified production benefits from use of climate-control or cooling technology (Armstrong, 1994; Bull et al., 1997; Mader and Davis, 2004). Without information about the use of these technologies, models cannot effectively incorporate parameters to estimate this benefit. Additionally, housing system has been shown to affect health, welfare, and productivity of animals (Ekkel et al., 1995, 1996). Until housing system parameters are reported consistently across studies, limited data are available to incorporate these influences into models.

Performance Data. Animal information makes up the most complex and most completely reported data type. A substantial opportunity for improving animal descriptions included in publications is to provide time-series data. In all studies, descriptions of animals (weight, age, parity, productivity) should be provided at the beginning, end, and at appropriate intervals during the experiment. When assessing growing animals, at a minimum, data should include start weight, end weight, days on feed, breed, and starting age. Key in- dicators of body composition (backfat thickness, BCS) are important and, when possible, composition of gain should be reported. Studies assessing lactating or laying animals should include basic age, parity (lactation), weight, and weight change parameters in addition to milk or egg yield and milk or egg composition (protein, sugars, fat, and fatty acid, as appropriate). Studies assessing reproductive efficiency should note conception rate and number of services required or breeding window, as appropriate. When taking blood samples, nutrient (glucose, fatty acids, amino acids, urea, VFA) and hormone concentrations should be thoroughly reported. Depending on the study focus, any measures of metabolic or physiological conditions that were collected should be included. Previous nutritional history and plane of nutrition are also important to report because the preceding conditions of the animal have real and significant effects on the future requirements and responses to nutritional changes (e.g., feeding in late pregnancy for an early-lactation cow; energy intake in the first 6 mo of age for studies on animals in later growth).

\section{Experimental Design and Data Reporting}

Animal scientists typically use some sort of factorial arrangement to design experiments. Although reporting data for the mean response in one factor across levels of another factor is a common practice, complete data reporting requires treatment means for each factor combination. Presenting these mean response data 


\section{Housing Conditions}

Housing system details

- Dimensions of housing unit

D Number of animals per housing unit

- Feeder and waterer space available per animal

- Type of housing structure

ㅁ Environmental measurements

- Temperature (mean, low, high)

口 Relative humidity

$\square$ Wind speed

Climate control systems

D Description of cooling system (fans, sprinklers, etc.)

- Temperature in housing system during cooling

$\square$ Temperature between cooling events
Exercise level (distance walked, elevation change)

- Terrain description

- Hilly or flat terrain

$\square$ Stocking density

$\square$ Health description

I Illnesses occurring

- Rate of illness occurrence

a Available subclinical indicators of illness

\section{Feed Parameters}

- Names and IFN for all feedstuffs

- Proportion of all feedstuffs within diet

- Nutrient composition of feedstuffs

ㅁ Energy (GE, DE, ME, NE)

- Protein (CP, amino acids)

a Carbohydrates (starch, fiber, sugars)

- Fat (EE, crude fat, fatty acids)

V Vitamins (A, D, E, B)

$\square \quad$ Minerals (macro and micro)

- Digestibility of feed or nutrients

- Shaker box of particle size measurements

- Physical form of feeds (ground, pelleted, etc.)
- Assays used to measure feed composition

- AOAC number for assays

- Any modifications to assays

口 Pasture studies

$\square$ Dates pasture or range was measured

口 Pasture nutrient composition at each date

$\square$ Digestibility at each date

- Stage of maturity

$\square$ Yield

\begin{tabular}{|c|c|c|c|}
\hline & \multicolumn{3}{|c|}{ Animal Descriptions } \\
\hline \multirow[t]{5}{*}{$\square$} & Animal profile & $\square$ & Lactation measurements \\
\hline & $\square$ Start weight & & 口 Milk yield and composition \\
\hline & $\square$ End weight & & - Milkings per day \\
\hline & 口 Start age & & 口 Days in milk \\
\hline & $\square$ End age & $\square$ & Egg production measurements \\
\hline \multirow[t]{5}{*}{$\square$} & Growth or gain measurements & $\square$ & Reproductive measurements \\
\hline & 口 Average daily gain & & 口 Conception rate \\
\hline & $\square$ Lean tissue growth rate & & $\square$ Live offspring per animals exposed \\
\hline & $\square$ Backfat thicloness & & - Estrus synchronization protocol \\
\hline & $\square \quad$ Start and end body condition score & $\square$ & Previous plane of nutrition \\
\hline \multirow{2}{*}{ 口 } & G Genotypic measures (if applicable) & & 口 All available metabolites measured \\
\hline & $\square$ Mature body weight & & $\square$ Site of measurement \\
\hline
\end{tabular}

Figure 1. Checklist for data that should be included in publications. Many of the parameters will not be available across different study types. This list can be used to guide authors, reviewers, and editors to ensure maximum efficiency in data reporting. 
is often justified by lack of statistical significance in the measured response data. However, there may be multiple reasons for failing to detect a statistically significant response. Study measurements are affected by uncontrolled experimental factors, measurement technique and equipment, or simply unknown variation. When assessing studies individually, it is difficult to ascertain how these experimental differences can bias results; however, when assessed from a meta-analytic standpoint, these exogenous sources of variation can be identified and their relationship with the response variables can be quantified (Thompson and Sharp, 1999; Higgins and Thompson, 2002). When treatment means are not reported, limited data are available for metaanalysis and identifying a global relationship between parameters is difficult.

Another important aspect of all collected and reported data are the variance structure and various measures of dispersion. In many cases, means and standard deviations or standard errors of the mean are not sufficiently robust to fully understand the scope of the animal sample being used or the variation in treatment or other response. Although figures and tables in most publications by necessity must be summaries, it is simple to include ranges (e.g., of feed chemical compositions, starting BW, age, DIM) that better define the study population, as well as means and ranges in response variables.

Defining relevant data within a study is a substantial barrier to improving the completeness and consistency of data reporting in animal science studies. For example, in a study assessing hormone or metabolite responses to varying levels of nutritional input, it may seem inappropriate or extraneous to include information on housing parameters or genetic merit. However, this is not correct, as we clearly understand that genetic variation and housing conditions will result in variation in response to nutrient intake or hormonal functions. Several examples have been supplied in the list of references; one is the series of studies demonstrating how dairy cattle from bulls of different genetic merit for milk production had specific metabolic differences in pathway flux and mRNA expression in adipose tissue (McNamara and Hillers, 1989; Khan et al., 2013; Rocco and McNamara, 2013). Including such detail will help us determine common responses and which are variable due to genetic background and the extent of the variation.

In most experiments, a treatment is applied over time and a series of measurements is taken during the experimental timeframe. Although mean responses over the entire experiment are generally reported, inclusion of the intermediate time-series data would greatly improve data availability for modeling investigations.
Time-series data are remarkably useful in fitting, evaluating, and improving mathematical models as most nutrition models have some dynamic consideration, whether the model is formally dynamic or static. By collecting information over a period of time, more data are available to better specify how relationships change with time, production level, age, BW, and other related factors. Furthermore, time-series data more precisely relate animal performance to nutritional inputs and relevant covariates. Because experiments are conducted over time, treatment means, by necessity, are the average response over a wide range of $\mathrm{BW}$, age, production level, and so on. Time-series data improve precision in estimating these relationships because smaller ranges are assumed in the data set (i.e., BW ranges over $1 \mathrm{wk}$ rather than $3 \mathrm{mo}$ ).

A final reporting opportunity that will be necessary to the improvement of future nutrition models is sharing individual animal data wherever possible, in the manuscript, in a managed database, or by personal communication. Although this level of detail is likely inappropriate in a print publication, online supplementary material is an appropriate location, and online data repositories (NANP, http://nanp-nrsp-9.org/) have been made available specifically for this type of data. Individual animal information is essential to fitting model responses or evaluating the availability of a model to accurately represent the responses in animals of differing genetic merit. A shift in research culture toward sharing individual animal data will greatly improve opportunities to incorporate genetic improvement into future nutrition models. This shift needs to occur concurrently with discussions on appropriate metrics of genetic merit so that as individual response data becomes available, useful genetic parameters can also be reported.

\section{Options for Data Sharing and Reporting}

True scientific and quantitative understanding comes from analysis of a body of knowledge, not usually from a single or small number of studies. One study obviously cannot answer all questions at once, thus data reviews, data mining, and meta-analytical techniques are powerful tools to bring us to a more sophisticated understanding. Inherent in the ability to do such work is the willingness and ability to share all data, not just data published in tables or figures. Most often, access to individual data such as animal weights, individual intakes, and milk production and composition is necessary to fully analyze and understand the biology involved. For good reason, not all data collected can always be included in a publication, but it is now standard practice (and, in fact, required for many studies 
in the United States and other countries) that data be made available, either in an accessible repository or upon request. Making sure these data are available in a common location will improve research efficiency. Recent research support efforts have developed a common location for preservation and distribution of modeling data (https://nanp-nrsp-9.org/perf/search/?anim $\mathrm{al}=$ all\&dataset $=$ all\&table $=$ Studies\&column $=$ Year\&c omparator $=$ exact\&value $=$ ), for the discussion of currently available nutrient requirement models (https:// nanp-nrsp-9.org/forum/), and examples of model codes (https://nanp-nrsp-9.org/resources/examples/).

\section{CONCLUSIONS}

Our biological understanding of animal production has advanced and now necessitates complex hypotheses integrating multiple systems with interacting factors. As experiments are designed to test these hypotheses, the design process should be conducted to produce data that are conducive to improving and advancing models of animal metabolism, nutrient requirements, and production. To make better use of research resources, enhanced integration between model-based research and experimental research should be a primary focus. Making data available in a consistent form within research publications and in supported and managed databases that are available to researchers will be paramount in this effort and will greatly advance biological understanding of livestock production.

\section{ACKNOWLEDGMENTS}

This work was carried out and supported as an activity of the National Animal Nutrition Program (NANP) to provide enabling technologies, support, and shared resources to the research community. The NANP, a National Research Support Project (NRSP-9) of State Agricultural Experiment Stations, is funded from Hatch funds administered by the USDA National Institute of Food and Agriculture (Washington, DC).

\section{REFERENCES}

Agnew, R. E., T. Yan, J. J. Murphy, C. P. Ferris, and F. J. Gordon. 2003. Development of maintenance energy requirement and energetic efficiency for lactation from production data of dairy cows. Livest. Prod. Sci. 82:151-162.

Armstrong, D. V. 1994. Heat stress interaction with shade and cooling. J. Dairy Sci. 77:2044-2050.

Arriola Apelo, S. I., J. R. Knapp, and M. D. Hanigan. 2014. Invited review: Current representation and future trends of predicting amino acid utilization in the lactating dairy cow. J. Dairy Sci. 97:4000-4017.

Baker, J. F., and D. Lunt. 1990. Comparison of production characteristics from birth through slaughter of calves sired by Angus, Charolais or Piedmontese bulls. J. Anim. Sci. 68:1562-1568.
Baldwin, R. L. 1995. Modeling Ruminant Digestion and Metabolism. Chapman and Hall, London, UK.

Baldwin, R. L., J. France, D. E. Beever, M. Gill, and J. H. Thornley. 1987a. Metabolism of the lactating cow: I. Animal elements of a mechanistic model. J. Dairy Res. 54:77-105.

Baldwin, R. L., J. France, and M. Gill. 1987b. Metabolism of the lactating cow. II. Digestive elements of a mechanistic model. J. Dairy Res. 54:107-131.

Baldwin, R. L., and R. Sainz. 1995. Energy partitioning and modeling in animal nutrition. Annu. Rev. Nutr. 15:191-211.

Baldwin. R. L., J. H. M. Thornley, and D. E. Beever. 1987c. Metabolism of the lactating cow: III. Properties of mechanistic models suitable for evaluation of energetic relationships and factors involved in the partition of nutrients. J. Dairy Res. 54:133-145.

Bannink, A., J. France, S. Lopez, W. J. J. Gerrits, E. Kebreab, S. Tamminga, and J. Dijkstra. 2008. Modelling the implication of feeding strategy on rumen fermentation and functioning of the rumen wall. Anim. Feed Sci. Technol. 143:3-26.

Bannink, A., J. Kogut, J. Dijkstra, J. France, E. Kebreab, A. M. Van Vuuren, and S. Tamminga. 2006. Estimation of the stoichiometry of volatile fatty acid production in the rumen of lactating dairy cows. J. Theor. Biol. 238:36-51.

Bannink, A., J. Kogut, J. Dijkstra, J. France, S. Tamminga, and A. M. Van Vuuren. 2000. Modelling production and portal appearance of volatile fatty acids in cows. Pages 87-102 in Modelling Nutrient Utilisation in Farm Animals. J. P. McNamara, J. France, and D. E. Beever, ed. CAB International, Wallingford, UK.

Beauchemin, K. A., H. H. Janzen, S. M. Little, T. A. McAllister, and S. M. McGinn. 2010. Life cycle assessment of greenhouse gas emissions from beef production in western Canada: A case study. Agric. Syst. 103:371-379.

Beukes, P. C., C. C. Palliser, K. A. Macdonald, J. A. Lancaster, G. Levy, B. S. Thorrold, and M. E. Wastney. 2008. Evaluation of a whole-farm model for pasture-based dairy systems. J. Dairy Sci. 91:2353-2360.

Black, J., B. Mullan, M. Lorschy, and L. Giles. 1993a. Lactation in the sow during heat stress. Livest. Prod. Sci. 35:153-170.

Black, J. L., G. T. Davies, and J. F. Fleming. 1993b. Role of computer-simulation in the application of knowledge to animal industries. Aust. J. Agric. Res. 44:541-555.

Blaxter, S. K. L. 1989. Energy Metabolism in Animals and Man. Cambridge University Press. Cambridge, UK.

Brody, S. 1945. Bioenergetics and growth; with special reference to the efficiency complex in domestic animals. Reinhold, Oxford, UK.

Brotherstone, S., I. White, and K. Meyer. 2000. Genetic modeling of daily milk yield using orthogonal polynomials and parametric curves. Anim. Sci. 70:407-415.

Brun, R., P. Reichert, and H. R. Künsch. 2001. Practical identifiability analysis of large environmental simulation models. Water Resour. Res. 37:1015-1030.

Bull, R. P., P. C. Harrison, G. L. Riskowski, and H. W. Gonyou. 1997. Preference among cooling systems by gilts under heat stress. J. Anim. Sci. 75:2078-2083.

Cannas, A., L. Tedeschi, D. Fox, A. N. Pell, and P. Van Soest. 2004. A mechanistic model for predicting the nutrient requirements and feed biological values for sheep. J. Anim. Sci. 82:149-169.

Carson, E. R., C. Cobelli, and L. Finkelstein. 1981. Modeling and identification of metabolic systems. Am. J. Physiol. 240:R120-R129.

Close, W. H. 1978. The effects of plane of nutrition and environmental temperature on the energy metabolism of the growing pig. 3. The efficiency of energy utilization for maintenance and growth. Br. J. Nutr. 40:433-438.

Cobelli, C., A. Lepschy, and G. R. Jacur. 1979. Identifiability of compartmental systems and related structural properties. Math. Biosci. $44: 1-18$.

Cornish-Bowden, A. 2005. Making systems biology work in the 21st century. Genome Biol. 6:317.

Cornish-Bowden, A., M. L. Cárdenas, J. C. Letelier, and J. SotoAndrade. 2007. Beyond reductionism: Metabolic circularity as a guiding vision for a real biology of systems. Proteomics 7:839-845. 
de Jong, H. 2002. Modeling and simulation of genetic regulatory systems: A literature review. J. Comput. Biol. 9:67-103.

Del Prado, A., P. Crosson, J. E. Olesen, and C. Rotz. 2013. Wholefarm models to quantify greenhouse gas emissions and their potential use for linking climate change mitigation and adaptation in temperate grassland ruminant-based farming systems. Animal $7: 373-385$.

Delgado, J. E., and J. Wolt. 2010. Fumonisin B1 and implications in nursery swine productivity: A quantitative exposure assessment. J. Anim. Sci. 88:3767-3777.

Dijkstra, J., H. Boer, J. Van Bruchem, M. Bruining, and S. Tamminga. 1993. Absorption of volatile fatty acids from the rumen of lactating dairy cows as influenced by volatile fatty acid concentration, $\mathrm{pH}$ and rumen liquid volume. Br. J. Nutr. 69:385-396.

Dijkstra, J., H. D. Neal, C. St, D. E. Beever, and J. France. 1992 Simulation of nutrient digestion, absorption and outflow in the rumen: Model description. J. Nutr. 122:2239-2256.

Doepel, L., D. Pacheco, J. Kennelly, M. Hanigan, I. Lopez, and H. Lapierre. 2004. Milk protein synthesis as a function of amino acid supply. J. Dairy Sci. 87:1279-1297.

Dym, C. 2004. Principles of Mathematical Modeling. Academic Press, Oxford, UK.

Ekkel, E. D., B. Savenije, W. Schouten, and M. Tielen. 1996. Health, welfare, and productivity of pigs housed under Specific-StressFree conditions in comparison with two-site systems. J. Anim. Sci. 74:2081-2087.

Ekkel, E. D., C. Van Doorn, M. Hessing, and M. Tielen. 1995. The Specific-Stress-Free housing system has positive effects on productivity, health, and welfare of pigs. J. Anim. Sci. 73:1544-1551.

FAO. 2009. How to Feed the World in 2050. Food and Agricultural Organization of the United Nations (FAO), Rome, Italy.

Firkins, J., L. Berger, and G. Fahey. 1985. Evaluation of wet and dry distillers grains and wet and dry corn gluten feeds for ruminants. J. Anim. Sci. 60:847-860.

Foley, S. L., A. Lynne, and R. Nayak. 2008. Salmonella challenges: Prevalence in swine and poultry and potential pathogenicity of such isolates. J. Anim. Sci. 86:E149-E162.

Ford, A. 2009. Modeling the Environment. Island Press Publishing, Washington DC

Fox, D. G., C. J. Sniffen, J. D. O'Connor, J. B. Russell, and P. J. Van Soest. 1992. A net carbohydrate and protein system for evaluating cattle diets: III. Cattle requirements and diet adequacy. J. Anim. Sci. 70:3578-3596.

Fox, D. G., L. O. Tedeschi, T. P. Tylutki, J. B. Russell, M. E. Van Amburgh, L. E. Chase, A. N. Pell, and T. R. Overton. 2004. The Cornell Net Carbohydrate and Protein System model for evaluating herd nutrition and nutrient excretion. Anim. Feed Sci. Technol. 112:29-78.

France, J., and J. H. Thornley. 1984. Mathematical Models in Agriculture. Butterworths, London, UK.

Freetly, H., J. Knapp, C. Calvert, and R. Baldwin. 1993. Development of a mechanistic model of liver metabolism in the lactating cow. Agric. Syst. 41:157-195.

Gentry, J. G., J. McGlone, J. Blanton, and M. Miller. 2002. Alternative housing systems for pigs: Influences on growth, composition, and pork quality. J. Anim. Sci. 80:1781-1790.

Ghimire, S., P. Gregorini, and M. D. Hanigan. 2014. Evaluation of predictions of volatile fatty acid production rates by the Molly cow model. J. Dairy Sci. 97:354-362.

Gill, J. L., and H. Hafs. 1971. Analysis of repeated measurements of animals. J. Anim. Sci. 33:331-336.

Grossman, M., T. Gossman, and W. Koops. 2000. A model for persistency of egg production. Poult. Sci. 79:1715-1724.

Haase, R. F., and M. V. Ellis. 1987. Multivariate analysis of variance. J. Couns. Psychol. 34:404

Hair, J. F., R. L. Tatham, R. E. Anderson, and W. Black. 2006. Multivariate Data Analysis. Pearson Prentice Hall, Upper Saddle River, NJ.

Hanigan, M. D., and R. Baldwin. 1994. A mechanistic model of mammary gland metabolism in the lactating cow. Agric. Syst. 45:369419 .
Hanigan, M. D., C. Palliser, and P. Gregorini. 2009. Altering the representation of hormones and adding consideration of gestational metabolism in a metabolic cow model reduced prediction errors. J. Dairy Sci. 92:5043-5056.

Hanigan, M. D., A. G. Ruis, E. S. Kolver, and C. C. Palliser. 2007. A redefinition of the representation of mammary cells and enzyme activities in a lactating dairy cow model. J. Dairy Sci. 90:38163830.

Higgins, J. P. T., and S. G. Thompson. 2002. Quantifying heterogeneity in a meta-analysis. Stat. Med. 21:1539-1558.

Hill, G. M., R. Gates, and G. Burton. 1993. Forage quality and grazing steer performance from Tifton 85 and Tifton 78 bermudagrass pastures. J. Anim. Sci. 71:3219-3225.

Holsheimer, J. P., and C. Veerkamp. 1992. Effect of dietary energy, protein, and lysine content on performance and yields of two strains of male broiler chicks. Poult. Sci. 71:872-879.

Hood, L., and N. D. Price. 2014. Editorial: Demystifying disease, democratizing health care. Sci. Transl. Med. 6:225ed5.

Hood, L., and L. Rowen. 2013. The Human Genome Project: Big science transforms biology and medicine. Genome Med. 5:79. http:// dx.doi.org/10.1186/gm483.

Huber, K., A. Kenez, J. P. McNamara, and S. L. Shields. 2014. Development of a dynamic, mechanistic model of nutritional and reproductive processes in dairy cattle. Anim. Prod. Sci. 11:1914.

Ideker, T., T. Galitski, and L. Hood. 2001. A new approach to decoding life: Systems biology. Annu. Rev. Genomics Hum. Genet. $2: 343-372$.

IPCC. 2007. Climate Change 2007-Synthesis Report. Intergovernmental Panel on Climate Change, Geneva, Switzerland.

Jenkins, T. G., and C. Ferrell. 1994. Productivity through weaning of nine breeds of cattle under varying feed availabilities: I. Initial evaluation. J. Anim. Sci. 72:2787-2797.

Jones, L. R. 2014. New forage index aids in dairy ration formulation. Feedstuffs Dec. 27, 2014. http://feedstuffs.com/story-new-forageindex-aids-dairy-ration-formulation-45-122039.

Jones, R. B., H. Blokhuis, and G. Beuving. 1995. Open-field and tonic immobility responses in domestic chicks of two genetic lines differing in their propensity to feather peck. Br. Poult. Sci. 36:525-530.

Kebreab, E., J. A. N. Mills, L. A. Crompton, A. Bannink, J. Dijkstra, W. J. J. Gerrits, and J. France. 2004. An integrated mathematical model to evaluate nutrient partition in dairy cattle between the animal and its environment. Anim. Feed Sci. Technol. 112:131-154.

Kerr, B. J., J. T. Yen, J. Nienaber, and R. Easter. 2003. Influences of dietary protein level, amino acid supplementation and environmental temperature on performance, body composition, organ weights and total heat production of growing pigs. J. Anim. Sci. 81:1998-2007.

Kertz, A. F. 1998. Variability in delivery of nutrients to lactating dairy cows. J. Dairy Sci. 81:3075-3084

Khan, M. J., A. Hosseini, S. Burrell, S. M. Rocco, J. P. McNamara, and J. Loor. 2013. Change in subcutaneous adipose tissue metabolism and gene network expression during the transition period in dairy cows, including differences due to sire genetic merit. J. Dairy Sci. 96:2171-2182.

Kitano, H. 2002. Computational systems biology. Nature 420:206-210.

Kleiber, M. 1961. The Fire of Life: An Introduction to Animal Energetics. Kleiber Publishing, New York, NY.

Lapierre, H., R. Berthiaume, G. Raggio, M. C. Thivierge, L. Doepel, D. Pacheco, P. Dubreuil, and G. E. Lobley. 2005. The route of absorbed nitrogen into milk protein. Anim. Sci. 80:11-22.

Laubichler, M. D., and G. B. Müller. 2007. Modeling Biology: Structures, Behavior, Evolution. MIT Press, Cambridge, MA.

Lean, I. J., M. C. Lucy, J. P. McNamara, B. J. Bradford, E. Block, J. M. Thomson, J. M. Morton, P. Celi, A. R. Rabiee, J. E. P. Santos, W. W. Thatcher, and S. J. LeBlanc. 2016. Recommendations for reporting intervention studies on reproductive performance in dairy cattle: Improving design, analysis, and interpretation of research on reproduction. J. Dairy Sci. 99:1-17.http://dx.doi. org/10.3168/jds.2015-9445. 
Littell, R. C., P. Henry, and C. Ammerman. 1998. Statistical analysis of repeated measures data using SAS procedures. J. Anim. Sci. 76:1216-1231.

Lofgreen, G., and W. Garrett. 1968. A system for expressing net energy requirements and feed values for growing and finishing beef cattle. J. Anim. Sci. 27:793-806.

Mader, T. L., and M. Davis. 2004. Effect of management strategies on reducing heat stress of feedlot cattle: Feed and water intake. J. Anim. Sci. 82:3077-3087.

Marcondes, M. I., L. O. Tedeschi, S. C. Valadares Filho, and M. P. Gionbelli. 2013. Predicting efficiency of use of metabolizable energy to net energy for gain and maintenance of Nellore cattle. J. Anim. Sci. 91:4887-4898.

McGlone, J. J., R. Nicholson, J. Hellman, and D. Herzog. 1993. The development of pain in young pigs associated with castration and attempts to prevent castration-induced behavioral changes. J. Anim. Sci. 71:1441-1446.

McMillian, I. 1981. Compartmental model analysis of poultry egg production curves. Poult. Sci. 60:1549-1551.

McNamara, J. P. 2004. Research, improvement and application of mechanistic, biochemical, dynamic models of metabolism in lactating dairy cattle. Anim. Feed Sci. Technol. 112:155-176.

McNamara, J. P. 2012. Integrating nutritional, genetic and reproductive management in early lactation dairy cattle. J. Anim. Sci 90:1846-1854

McNamara, J. P., and R. Baldwin. 2000. Estimation of parameters describing lipid metabolism in lactation: Challenge of existing knowledge described in a model of metabolism. J. Dairy Sci. 83:128-143.

McNamara, J. P., and J. K. Hillers. 1989. Regulation of bovine adipose tissue metabolism during lactation. 5. Relationships of lipid synthesis and lipolysis with energy intake and utilization. J. Dairy Sci. 72:407-418.

McNamara, J. P., K. Huber, and A. Kenez. 2016. A dynamic, mechanistic model of metabolism in adipose tissue of lactating dairy cattle. J. Dairy Sci. 99:5649-5661.

McNamara, J. P., and S. L. Shields. 2013. Reproduction during lactation of dairy cattle: integrating nutritional aspects of reproductive control in a systems research approach. Anim. Front. 3:76-83.

Metcalf, J. A., R. J. Mansbridge, J. S. Blake, J. D. Oldham, and J. R. Newbold. 2008. The efficiency of conversion of metabolisable protein into milk true protein over a range of metabolisable protein intakes. Animal 2:1193-1202.

Milligan, L. P., and B. W. McBride. 1985. Symposium: Shifts in animal energy requirements across physiological and alimentation states. J. Nutr. 115:1374-1382.

Moe, P. W., and H. F. Tyrrell. 1975. Efficiency of conversion of digested energy to milk. J. Dairy Sci. 58:602-610.

Mogilner, A., R. Wollman, and W. F. Marshall. 2006. Quantitative modeling in cell biology: What is it good for? Dev. Cell 11:279-287.

Mugnai, C., A. Dal Bosco, and C. Castellini. 2009. Effect of rearing system and season on the performance and egg characteristics of Ancona laying hens. Ital. J. Anim. Sci. 8:175-188.

Müller, M., and S. Kersten. 2003. Nutrigenomics: Goals and strategies. Nat. Rev. Genet. 4:315-322.

Nicholson, J. K., E. Holmes, J. C. Lindon, and I. D. Wilson. 2004. The challenges of modeling mammalian biocomplexity. Nat. Biotechnol. 22:1268-1274.

Nienaber, J. A., G. Hahn, and R. Eigenberg. 1999. Quantifying livestock responses for heat stress management: A review. Int. J. Biometeorol. 42:183-188.

Noguera, J. L., L. Varona, D. Babot, and J. Estany. 2002. Multivariate analysis of litter size for multiple parities with production traits in pigs: II. Response to selection for litter size and correlated response to production traits. J. Anim. Sci. 80:2548-2555.

NRC. 1994. Nutrient Requirements of Poultry. 9th rev. ed. National Academies Press, Washington, DC.

NRC. 2001. Nutrient Requirements of Dairy Cattle. 7th ed. National Academies Press, Washington, DC.

NRC. 2007. Nutrient Requirements of Small Ruminants: Sheep, Goats, Cervids, and New World Camelids. 1st ed. Natl. Acad. Press, Washington, DC.
NRC. 2012. Nutrient Requirements of Swine. 11th rev. ed. National Academies Press, Washington, DC.

NRC. 2016. Nutrient Requirements of Beef Cattle. 8th rev. ed. National Academies Press, Washington, DC.

O'Connor, J. D., C. Sniffen, D. Fox, and W. Chalupa. 1993. A net carbohydrate and protein system for evaluating cattle diets: IV Predicting amino acid adequacy. J. Anim. Sci. 71:1298-1311.

Oldham, J. D. 1984. Protein-energy interrelationships in dairy cows. J. Dairy Sci. 67:1090-1114

Olson, K. M., B. G. Cassell, and M. D. Hanigan. 2010. Energy balance in first-lactation Holstein, Jersey, and reciprocal F-1 crossbred cows in a planned crossbreeding experiment. J. Dairy Sci. 93:4374-4385

Ott, R. L., and M. Longnecker. 2010. An Introduction to Statistical Methods and Data Analysis. 6th ed. Brooks/Cole, Belmont, CA.

Ouellet, D. R., M. Demers, G. Zuur, G. E. Lobley, J. R. Seoane, J. V. Nolan, and H. Lapierre. 2002. Effect of dietary fiber on endogenous nitrogen flows in lactating dairy cows. J. Dairy Sci. 85:3013-3025.

Passmore, C., and J. Stewart. 2002. A modeling approach to teaching evolutionary biology in high schools. J. Res. Sci. Teach. 39:185204.

Reverter, A., Y. Y. Yang, K. A. Byrne, S. H. Tan, G. S. Harper, and S. A. Lehnert. 2004. Joint analysis of multiple cDNA microarray studies via multivariate mixed models applied to genetic improvement of beef cattle. J. Anim. Sci. 82:3430-3439.

Rocco, S. M., and J. P. McNamara. 2013. Regulation of bovine adipose tissue metabolism during lactation. 7. Metabolism and gene expression as a function of genetic merit and dietary energy intake. J. Dairy Sci. 96:3108-3119.

Rotz, C. A., D. Buckmaster, and J. Comerford. 2005. A beef herd model for simulating feed intake, animal performance, and manure excretion in farm systems. J. Anim. Sci. 83:231-242.

Russell, J. B., J. O'connor, D. Fox, P. Van Soest, and C. Sniffen. 1992 A net carbohydrate and protein system for evaluating cattle diets: I. Ruminal fermentation. J. Anim. Sci. 70:3551-3561.

Schils, R., J. E. Olesen, A. Del Prado, and J. Soussana. 2007. A review of farm level modeling approaches for mitigating greenhouse gas emissions from ruminant livestock systems. Livest. Sci. 112:240251.

Schinckel, A., N. Li, P. Preckel, M. Einstein, and D. Miller. 2003. Development of a stochastic pig compositional growth model. Prof. Anim. Sci. 19:255-260.

Schwager-Suter, R., C. Stricker, D. Erdin, and N. Kunzi. 2001. Net energy efficiencies of Holstein, Jersey and Holstein-Jersey F1crosses. Anim. Sci. 72:335-342.

Shimmura, T., Y. Eguchi, K. Uetake, and T. Tanaka. 2007. Behavior, performance and physical condition of laying hens in conventional and small furnished cages. Anim. Sci. J. 78:323-329.

Sniffen, C. J., J. O'Connor, P. Van Soest, D. Fox, and J. Russell. 1992. A net carbohydrate and protein system for evaluating cattle diets: II. Carbohydrate and protein availability. J. Anim. Sci 70:3562-3577.

St-Pierre, N., B. Cobanov, and G. Schnitkey. 2003. Economic losses from heat stress by US livestock industries. J. Dairy Sci. 86:E52E77.

St-Pierre, N. R. 2001. Invited review: Integrating quantitative findings from multiple studies using mixed model methodology. J. Dairy Sci. 84:741-755.

St-Pierre, N. R. 2007. Design and analysis of pen studies in the animal sciences. J. Dairy Sci. 90(E-Suppl.):E87-E99.

Steele, R. G. D., and J. H. Torrie. 1980. Principles and Procedures of Statistics. A Biometrical Approach. 2nd ed. McGraw-Hill, New York, NY

Sykes, A. 1994. Parasitism and production in farm animals. Anim. Sci. 59:155-172.

Tedeschi, L. O. 2006. Assessment of the adequacy of mathematical models. Agric. Syst. 89:225-247.

Tedeschi, L. O., C. Boin, D. G. Fox, P. R. Leme, G. F. Alleoni, and D. P. D. Lanna. 2002. Energy requirement for maintenance and growth of Nellore bulls and steers fed high-forage diets. J. Anim. Sci. 80:1671-1682. 
Tedeschi, L. O., D. G. Fox, G. E. Carstens, and C. L. Ferrell. 2010. The partial efficiency of use of metabolizable energy to net energy for growth in ruminants. Pages 519-529 in Proc. 3rd Int. Symp. Energy and Protein Metabolism and Nutrition, Parma, Italy. Wageningen Academic Publishers, Wageningen, the Netherlands.

Tedeschi, L. O., D. G. Fox, and P. J. Kononoff. 2013. A dynamic model to predict fat and protein fluxes associated with body reserve changes in cattle. J. Dairy Sci. 96:2448-2463.

Tempelman, R. J. 2004. Experimental design and statistical methods for classical and bioequivalence hypothesis testing with an application to dairy nutrition studies. J. Anim. Sci. 82(E-Suppl.):E162E172.

Tempelman, R. J. 2009. Invited review: Assessing experimental designs for research conducted on commercial dairies. J. Dairy Sci. 92:1-15.

Thompson, S. G., and S. J. Sharp. 1999. Explaining heterogeneity in meta-analysis: A comparison of methods. Stat. Med. 18:2693-2708.

Thornley, J. H., and J. France. 2006. Mathematical Models in Agriculture: Quantitative Methods for the Plant, Animal and Ecological Sciences. 2nd ed. CABI, Cambridge, MA.

Thornley, J. H. M., and J. France. 1984. Role of modeling in animal production research and extension work. In Modeling Ruminant Digestion and Metabolism. R. L. Baldwin and A. C. Bywater, ed. Department of Animal Science, University of California-Davis.

Todaro, M., M. L. Scatassa, and P. Giaccone. 2005. Multivariate factor analysis of Girgentana goat milk composition. Ital. J. Anim. Sci. 4:403.
Tylutki, T. P., D. G. Fox, V. M. Durbal, J. B. Russell, L. O. Tedeschi, and M. VanAmburgh. 2008. Cornell Net Carbohydrate and Protein System: A model for precision feeding of dairy cattle. Anim. Feed Sci. Technol. 143:174-202.

van Milgen, J., and J. Noblet. 1999. Energy partitioning in growing pigs: the use of a multivariate model as an alternative for the factorial analysis. J. Anim. Sci. 77:2154-2162.

Wang, Z., and L. A. Goonewardene. 2004. The use of MIXED models in the analysis of animal experiments with repeated measures data. Can. J. Anim. Sci. 84:1-11.

West, J. W. 2003. Effects of heat-stress on production in dairy cattle. J. Dairy Sci. 86:2131-2144.

Wheeler, T. L., J. Savell, H. Cross, D. Lunt, and S. Smith. 1990 Mechanisms associated with the variation in tenderness of meat from Brahman and Hereford cattle. J. Anim. Sci. 68:4206-4220.

Wilensky, U., and K. Reisman. 2006. Thinking like a wolf, a sheep, or a firefly: Learning biology through constructing and testing computational theories-An embodied modeling approach. Cogn. Instr. $24: 171-209$.

Wondra, K. J., J. Hancock, K. Behnke, R. Hines, and C. Stark. 1995. Effects of particle size and pelleting on growth performance, nutrient digestibility, and stomach morphology in finishing pigs. J. Anim. Sci. 73:757-763.

Yan, T., F. Gordon, R. Agnew, M. Porter, and D. Patterson. 1997. The metabolisable energy requirement for maintenance and the efficiency of utilisation of metabolisable energy for lactation by dairy cows offered grass silage-based diets. Livest. Prod. Sci. 51:141-150. 